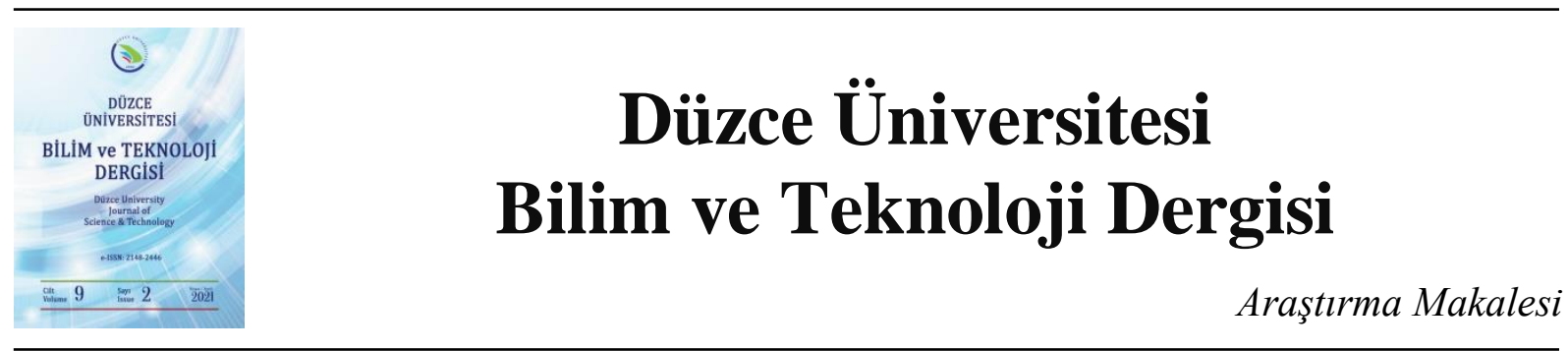

\section{Güç Sistemlerinde Sürekli ve Geçici Durum Gerilim Kararlılığının UPFC-Yakıt Hücresi ile İncelenmesi}

\author{
(iD M. Kenan DÖŞOĞLU ${ }^{\mathrm{a}, *}$, iD Tuba Emine BOZKURT ${ }^{\mathrm{b}}$ \\ ${ }^{a}$ Elektrik Elektronik Mühendisliği Bölümü, Mühendislik Fakültesi, Düzce Üniversitesi, Düzce, TÜRKIYE \\ ${ }^{b}$ Elektrik Elektronik ve Bilgisayar Mühendisliği Bölümü, Fen Bilimleri Enstitüsü, Düzce Üniversitesi, Düzce, \\ TÜRKIYE \\ * Sorumlu yazarın e-posta adresi: kenandosoglu@duzce.edu.tr \\ DOI:10.29130/dubited.850192
}

\begin{abstract}
ÖZET
Güç sistemlerinin sürekli ve geçici durum çalışmalarında Esnek AC İletim Sistemi (FACTS) cihazları tercih edilmektedir. FACTS cihazları içerisinde kontrol etme yeteneği en güçlü olan Birleştirilmiş Güç Akışı Kontrolü (UPFC)'dir. UPFC bara gerilimlerini reaktif güce bağlı olarak kontrol ederken, iletim hattını empedans ve akıma göre kontrol etmektedir. Bu çalışmada, Uluslararası Elektrik Elektronik Mühendisliği (IEEE) 14 baralı güç sisteminde UPFC'nin statik ve dinamik gerilim kararlılığı analizleri gerçekleştirilmiştir. Sürekli ve geçici durum için gerilim kararlılığı çalışma limitlerinin geliştirilmesi ve sistemin kararlı bölgede kalması için UPFC ile birlikte Enerji Depolama Sistemi (EDS) elemanlarından yakıt hücresi kullanılmıştır. UPFC-EDS ile sistemin gerilim-maksimum yüklenme parametre değerlerinin yanı sıra bara gerilim profilleri analiz edilmiştir. UPFC ile yakıt hücresinin birlikte kullanılması durumunda sistemin yüklenme parametre değerinin arttığı ve bara gerilim profillerinin iyileştiği görülmüştür.
\end{abstract}

Anahtar Kelimeler:UPFC, EDS, Gerilim-maksimum yüklenme parametresi

\section{Investigation with UPFC-Fuel Cellof Steady and Transient Voltage Stability in Power Systems}

\begin{abstract}
Flexible AC Transmission System (FACTS) devices are preferred for steady state and transient state of power systems. Unified Power Flow Control (UPFC) has best control capability among FACTS devices. While UPFC controls bus voltages depending on reactive power, it controls the transmission line according to impedance and current. In this paper, static and dynamic voltage stability analyzes of UPFC were tested in the International Electric Electronic Engineering (IEEE) 14 bus power system. Fuel cell, which is a kind of Energy Storage System (ESS) devices, was used together with UPFC to improve the voltage stability operating limits for the steady state and transient state and to keep the system in the stable region. Besides, the voltage-maximum loading parameter values of the system, the bus voltage profiles were analyzed with the UPFC-EDS. In case of using UPFC and fuel cell together, it was observed that the loading parameter value of the system increased and the bus voltage profiles improved.
\end{abstract}

Keywords:UPFC, EDS, Voltage-maximum loading parameter 


\section{GIiRIS}

Yarı iletken teknolojisinin hızlı gelişimi elektrik güç sistemlerinin güç elektroniği aygıtları vasıtasıyla kontrol edilmesini mümkün kılmaktadır. Bu cihazlar FACTS adı verilen yeni bir teknolojiyi oluşturmaktadır. FACTS teknolojisi, aktif-reaktif gücü kontrol etmek ve mevcut iletim sistemlerinin kullanılabilir kapasitesini arttırmak için yeni firsatlar sunmaktadır. FACTS cihazları içerisinde en gelişmiş olan model UPFC'dir. UPFC hem barayı hemde iletim hattındaki birçok parametreyi kontrol etmek amaçlı olarak kullanılabilmektedir. Literatürde UPFC ile ilgili yapılan çalışmalar incelenecek olursa; İletim hatları arasındaki aktif ve reaktif güç alış verişine bağlı olarak güç sisteminde kararlılık analizi ile küçük dağılmalar durumunda UPFC'nin etkin kullanımı incelenmektedir. Çok makinalı sistemlerde elektromekanik salınım ve güç osilasyon sönümlemelerinde UPFC küçük sinyal kararlılığı bakımından sistemin kararlı bölgede kalmasını sağlamaktadır [1,2]. Senkron generatör ve UPFC'de doğrudan kontrol modelleri ve ilave sinyal eklenmesi ile senkron altı rezonans analizleri incelenmektedir. Geliştirilen kontrol modelleri ve denetleyicileri sayesinde sistemdeki salınımların kısa sürede kararlı hale geldiği ve küçük sinyal kararlılığının etkili sonuçlar verdiği görülmektedir [35]. Çok makinalı güç sisteminde şebeke tarafinda oluşan olumsuz durumlara karşı meydana gelen güç kalitesi problemlerinin giderilmesinde dinamik zaman cevabını hızlı sağlaması açısından UPFC kullanılmaktadır. Aktif ve reaktif güç kontrolünün sağlanmasının yanısıra, güç kalitesi sorunlarını çözmede sisteme seri evirici devresindeki gerilim enjekte edilmesini sağlayan UPFC eş zamanlı olarak şebeke sinüsoidal şeklinin bozulması ile ortaya çıkan harmonikleri kısa sürede minimum düzeye indirmektedir [6, 7]. Güç sistemlerinde maksimum transfer kapasitesini arttırmak, iletim hattı gücünü arttırmak ve istenilen aktif-reaktif güç profilini ortaya çıkartmak için UPFC iç çalışma noktası metodu kullanılmaktadır. İç çalışma noktası metodu ile UPFC'nin en optimum değerler alması sağlanarak UPFC bağlantı noktası ve gerçek generatör eşdeğer durumlarının belirlenmesi çok baralı güç sistemlerinde UPFC'nin daha etkin olarak bulunmasını sağlamış olmaktadır [8,9]. UPFC'nin güç sistemlerinde diğer kullanım alanlarından birisi de paralel evirici devresindeki güç enjekte modellemesidir. Güç sistemlerinde UPFC'nin en optimum çalışma yerinin belirlenmesi ile iletim hattının başlangıç ve bitiş noktaları arasında eş zamanlı olarak güç denetimi yapılmaktadır. Özelliklede paralel evirici devresinde gerçekleşen güç enjekte modellemesi sayesinde her iki evirici devresindeki anahtarlama kayıpları ve hat kopması problemlerini ortadan kaldırmada etkili olduğu gözlemlenmektedir [10, 11]. Farklı test sistemlerinde tahminci ve düzeltici iterasyon adımları yapılarak güç sistemlerinin maksimum yüklenme parametre değerlerini iyileştirmek için UPFC kullanılmaktadır. Özellikle yük baralarındaki gerilim profillerindeki iyileşme yüklenme durumu açısından önemli bir konu olarak karşımıza çıkmaktadır [12-14].

Yapılan bu çalışmada maksimum yüklenme parametre değerini arttırma ve güç sistemlerinin çalışma koşullarının daha iyi hale getirilmesi için UPFC ile birlikte EDS elemanlarından yakıt hücresi kullanılmıştır. Sistemin normal çalışması statik gerilim kararlılığı analizi olarak incelenirken, hatta bulunan kesicinin belirli bir süre devre dışı kalıp tekrar devreye girmesi dinamik gerilim kararlılığ sınıfı altında incelenmiştir. Her iki durumdaki gerilim kararlılığı analizi sonuçlarına göre UPFCEDS'nin sistemin maksimum yüklenme değerlerini arttırırken, yük baralarının gerilim profillerini de sürekli yük akışında iyileştirdiği görülmüştür. 


\section{BİRLESTIRILMISS GÜC AKIȘI KONTROLÜ (UPFC)}

UPFC devre modeli Şekil 1'de gösterilmiştir.

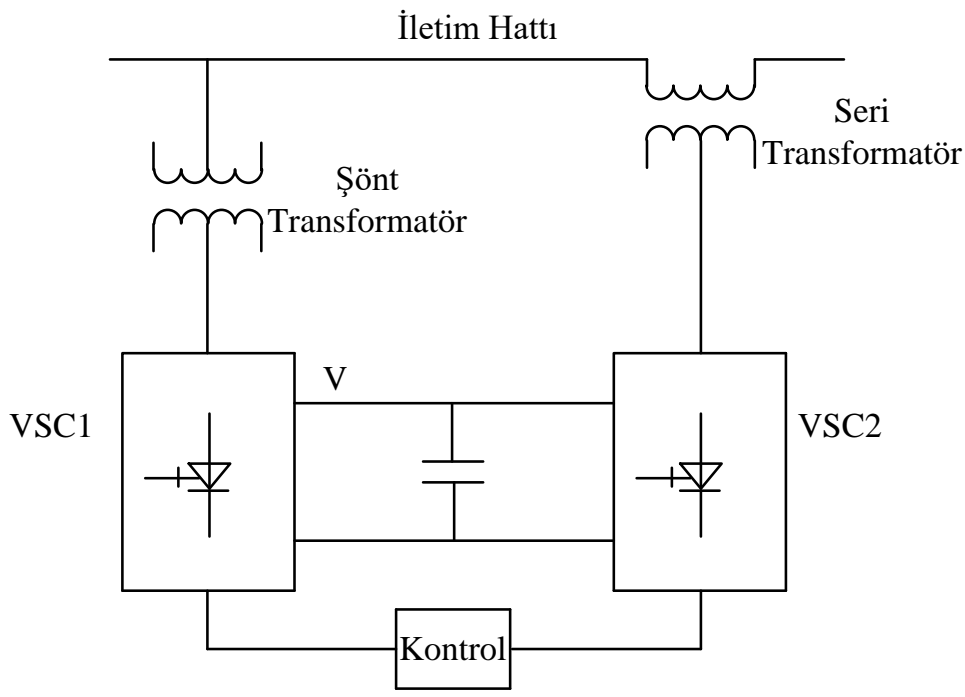

Şekil 1.UPFC devre modeli

Şekil 1'de yer alan UPFC devre modeli incelendiğinde, UPFC'nintristör tetikleme devreleri kullanılan gerilim kaynaklı eviricilerden oluştuğu görülmektedir [15].

VSC1 ve VSC2 olarak adlandırılan bu eviricilerin çalışmasında, bir DC depolama kapasitörünün sağladığı ortak bir DC bağlantı kullanılmaktadır. Buna bağlı olarak AC güç dönüştürücüde, aktif güç iki eviricinin AC terminalleri ile her bir evirici arasındaki iki yönde serbest bir şekilde akabilmektedir ve $\mathrm{AC}$ güç dönüştürücü, kendi $\mathrm{AC}$ çıkış terminalinde reaktif gücü çekmenin yanı sıra bağımsız olarak üretebilmektedir.

VSC1 ve VSC2 arasındaki güç alışverişinde seri olarak enjekte edilen gerilimden yararlanılmasına rağmen, buradaki reaktif gücün tamamı evirici 2 üzerinden sağlanmaktadır. Buna bağlı olarak evirici 1, birleşik güç faktöründe çalıştırılabilir veya hat ile reaktif bir güç alışverişine sahip olacak şekilde ve evirici 2 tarafından değiştirilen reaktif güçten bağımsız bir biçimde kontrol edilebilir. UPFC'nin güç sistemindeki aktif ve reaktif güç kontrolü iki makinalı sistemde gösterilmektedir. UPFC'nin iki makinalı sistemdeki gösterimi ve gerilim fazör diyagramı Şekil 2 ve Şekil 3 'te yer almaktadır.

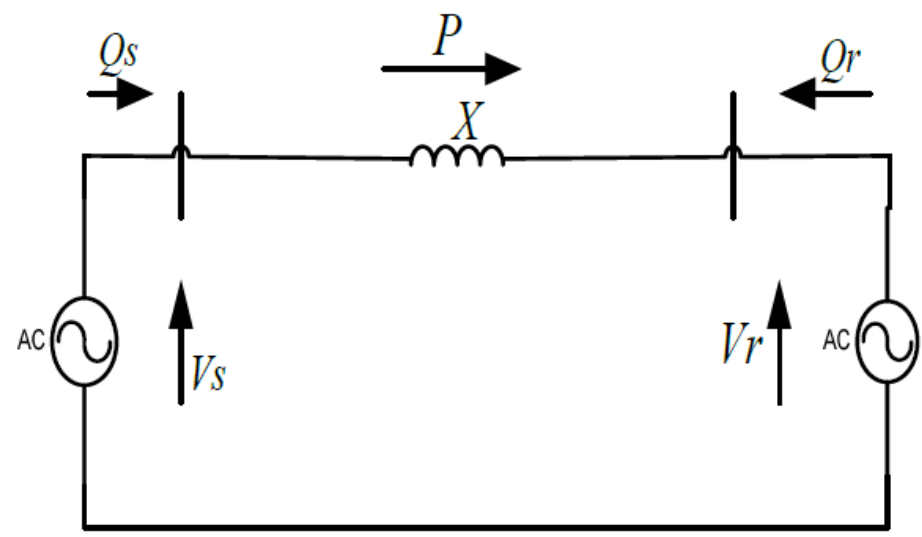

Şekil 2.UPFC'nin iki makinall sistemde gösterimi 


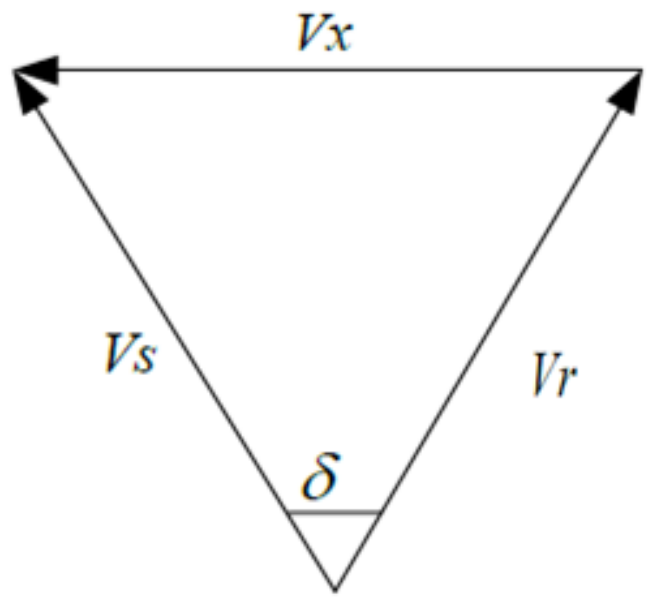

Şekil 3.UPFC'nin gerilim fazör diyagramı

Şekil 2'de yer alan $\mathrm{V}_{\mathrm{s}}$ kaynak uç gerilimini, $\mathrm{V}_{\mathrm{r}}$ alıcı uç gerilimini ve $\mathrm{X}$ hat empedansını ifade etmektedir. Şekil 3'te ise UPFC gerilimleri fazörolarak, $\delta$ ve $\mathrm{V}_{\mathrm{s}}=\mathrm{V}_{\mathrm{r}}=\mathrm{V}$ iletim açıları ile ifade edilmiştir. Hattan iletilen aktif ve reaktif güce ait ifadeler denklem (1) ve denklem (2)'de yer almaktadir.

$P=\frac{V^{2}}{X} \sin \delta$

$Q=Q_{S}=Q_{r}=\frac{V^{2}}{X} \cos \delta$

$\mathrm{Bu}$ denklemlerde yer alan, $\mathrm{P}$ ifadesi hattan akan aktif güç iken, $\mathrm{V}$ hat gerilimi ve $\delta$ faz açısıdır.Şekil 4 'te iki makinalı temel güç sisteminin UPFC ile geliştirilmiş modeli yer almaktadır.

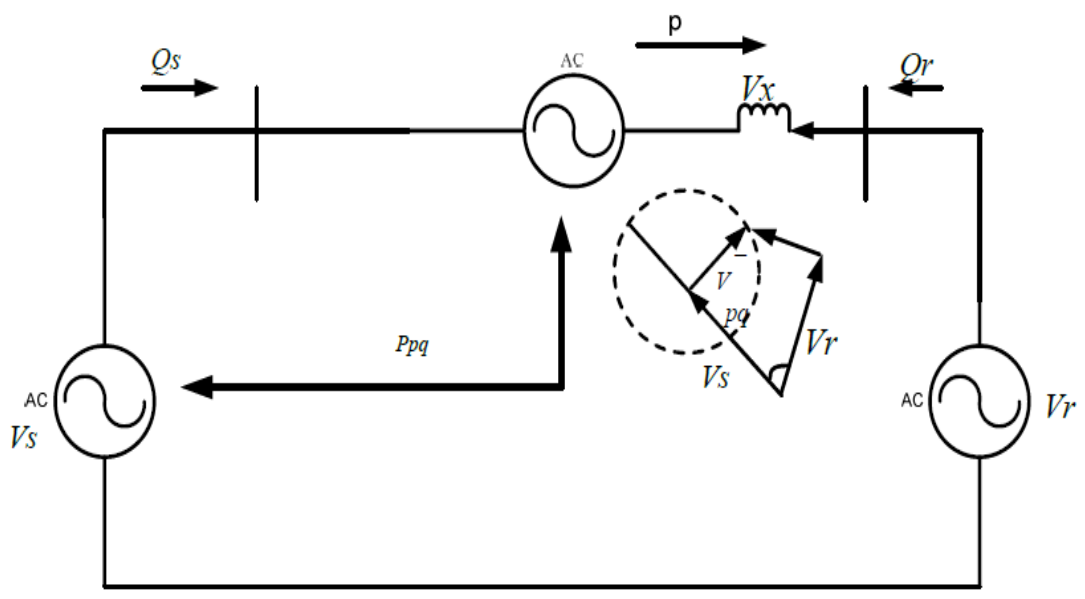

Şekil 4. İki makinalı güç sisteminin UPFC ile geliş̧tirilmiş modeli

UPFC'nin iletilen aktif gücü ile kaynak ve alıcı ucundan sırasılylaQ $Q_{s}$ ve $Q_{r}$ reaktif güç taleplerini kontrol etme kabiliyetini ortaya koyacak bir amacın temin edilmesini sağlar. UPFC tarafindan hatla seri olarak enjekte edilen gerilim, fazör $\mathrm{V}$ ile ifade edilir, $V_{p q}\left(0 \leq V_{p q} \leq 0.5 p . u\right)$ büyüklüğ̈̈ ve $\rho\left(0 \leq \rho \leq 360^{\circ}\right)$ arasında olacak şekilde faz konumuna göre ölçülür. I fazörü ile ifade edilen hat akımı, $\mathrm{V}_{\mathrm{pq}}$ seri gerilim kaynağı üzerinden akar ve hem reaktif hem de gerçek güç alışverişiyle sonuçlanır. UPFC'yi doğru şekilde temsil etmek için seri gerilim kaynağı yalnızca reaktif güç üretme 
şartına bağlanır ve hat ile alışverişte bulunur [15]. Böylece, hat ile karşılaştırma yapan aktif güç, gücün iki makinalı sistemde uygun değerinin belirlenmesinde önemli bir rol almış olur. Şekil 4'e göre, iki makinalı sistemde iletim hattı boyunca gerilimin tamamı iletim hattının $V_{s}+V_{p q}$ değeri ile ifade edilmektedir. UPFC ile iki makinalı sistemde gerilim ve aktif-reaktif güç ifadeleri denklem (3) ve denklem (4)'te gösterilmiştir.

$$
\begin{aligned}
& V_{p q}=\Delta V+V_{p}+V_{q} \\
& P-j Q=V_{r}\left(\frac{V_{s}+V_{p q}-V_{r}}{j X}\right)
\end{aligned}
$$

$\mathrm{V}_{\mathrm{pq}}=0$ olduğu durumda denklem (5) gibi elde edilir.

$$
P-j Q=V_{r}\left(\frac{V_{s}-V_{r}}{j X}\right)
$$

$\mathrm{V}_{\mathrm{pq}}=0$ ' eşit olmadığı durumdaki ifadesi denklem (6) elde edilir.

$$
P-j Q=V_{r}\left(\frac{\left(V_{s}-V_{r}^{*}\right)}{j X}\right)+\left(\frac{V_{r} V_{p q}^{*}}{-j X}\right)
$$

Kaynak gerilimi, alıcı uç gerilimi ve toplam p-q gerilim ifadeleri sırasıyla denklem (7) ve denklem (9) arasında gösterilmiştir.

$$
\begin{aligned}
& V_{s}=V e^{j \delta / 2}=V\left(\cos \frac{\delta}{2}+\sin \frac{\delta}{2}\right) \\
& V_{r}=V e^{-j \delta / 2}=V\left(\cos \frac{\delta}{2}-\sin \frac{\delta}{2}\right) \\
& V_{p q}=V e^{-j(\delta / 2+\rho)}=V_{p q}\left[\cos \left(\frac{\delta}{2}+\rho\right)-\sin \left(\frac{\delta}{2}+\rho\right)\right]
\end{aligned}
$$

İletim hattından akan aktif güç ve uç alıcı reaktif güç ifadeleri denklem (10) ve denklem (11)'de gösterilmiştir.

$$
\begin{aligned}
& P(\delta, \rho)=P_{0}(\delta)+P_{p q}(\rho)=\frac{V^{2}}{X} \sin \delta-\frac{V V_{p q}}{X} \cos \left(\frac{\delta}{2}+\rho\right) \\
& Q_{r}(\delta, \rho)=Q_{r 0}(\delta)+Q_{p q}(\rho)=\frac{V^{2}}{X}(1-\cos \delta)-\frac{V V_{p q}}{X} \sin \left(\frac{\delta}{2}+\rho\right)
\end{aligned}
$$

Burada, $\mathrm{P}_{0}$ ve $\mathrm{Q}_{\mathrm{r} 0}$ başlangıç aktif ve reaktif güç değerleridir. Başlangıç aktif ve reaktif güç ifadeleri denklem (12) ve denklem (13)'te gösterilmiştir.

$$
P_{0}(\delta)=\frac{V^{2}}{X} \sin \delta
$$


$Q_{r 0}(\delta)=\frac{V^{2}}{X}(1-\cos \delta)$

Burada, $\rho$ açısı iletim açısıdır. $\rho$ açısı 0 ile $2 \pi$ arasında değer alırken, $\delta$ faz açısı değeri 0 ile $\pi$ arasında değer almaktadır. $\mathrm{P}_{0}$ ve $\mathrm{Q}_{\mathrm{r} 0}$ başlangıç aktif ve reaktif güç değerlerinin almış olduğu değer aralığ1 denklem (14) ve denklem (15)'te gösterilmiştir.

$$
\begin{aligned}
& P_{0}(\delta)-\frac{V V_{\text {pqmaksimum }}}{X} \leq P_{0}(\delta) \leq P_{0}(\delta)+\frac{V V_{\text {pqmaksimum }}}{X} \\
& Q_{r 0}(\delta)-\frac{V V_{\text {pqmaksimum }}}{X} \leq Q_{r 0}(\delta) \leq Q_{r 0}(\delta)+\frac{V V_{\text {pqmaksimum }}}{X}
\end{aligned}
$$

Başlangıç aktif ve reaktif güç değerlerinde normal olarak iletilen güç ifadeleri denklem (16) ve denklem (17)'de gösterilmiştir.

$$
\begin{aligned}
& P_{0}(\delta)=\frac{V^{2}}{X} \sin \delta=\sin \delta \\
& Q_{r 0}(\delta)=\frac{V^{2}}{X}(1-\cos \delta)=1-\cos \delta
\end{aligned}
$$

\section{III.YAKIT HÜCRESI}

Yakıt hücresi sistemi elektrik üretimde, yakıt işlemcisi, yakıt hücresi devresi ve güç bağlantı ünitesi olmak üzere üç temel katmandan oluşmaktadır. Güç işlemcisi, yakıtın dönüşüme uğradığı kısımdır. Sistem içerisinde kullanılan elektrokimyasallar sayesinde elektriğin üretildiği kısım yakıt hücresi devresi olarak ifade edilir. Güç bağlantı ünitesi ise AC güç akım, gerilim ve frekans içeren bölge ve DC güce dönüssen kısımdır. Yakıt hücresi devresi DC güç üretmesine rağmen, bu kısımda üretilen güç gözlemlenebildiği ve ölçülebildiği için doğrudan kontrol edilemeyebilir. Güç bağlantı ünitesi şebekenin ihtiyacına göre AC gücü DC güce dönüştürme işleminin gerçekleştirildiği bölgedir [16].

Yakıt hücresi modelindeki yakıt hücre akımının sabit güç kontrolü ile hesaplanması denklem (18)'de gösterilmiştir.

$I_{k}=\frac{\left(P_{r e f} / V_{k 0}-i_{k}\right)}{T_{e}}$

Burada, yakıt hücresi akımı $\mathrm{I}_{\mathrm{k}}$, yakıt hücresi başlangıç $\mathrm{DC}$ gerilimi $\mathrm{V}_{\mathrm{k} 0}$, başlangıç yakıt hücresi akımı $\mathrm{i}_{\mathrm{k}}$, küçük zaman sabiti ise $\mathrm{T}_{\mathrm{e}}$ olarak ifade edilir. Bağlandığı sistemde giriş sinyalinin aşırı derecede büyük olması durumunda yakıt hücresinde akım hesaplaması denklem (19)'daverilmiştir.

$$
I_{k}=\left(\frac{U_{\text {limit }} q H_{2}}{2 K_{r}}-i_{k}\right) \frac{1}{T_{e}}
$$

Burada, $\mathrm{U}_{\text {limit }}$ minimum veya maksimum yakıt tüketimi, $\mathrm{H}_{2}$ hidrojen oranı, q soğutma katsayıs1, $\mathrm{K}_{\mathrm{r}}$ ise DC katsayısıdır. Yakıt hücresinin şebeke bağlantısı transformatör ve ideal bir evirici vasitasıyla sağlandığında, AC gerilim modülasyon genliği sayesinde ayarlanmaktadır. Modülasyon genlik ifadesinin türevli hali denklem (20)'de gösterilmiştir. 


$$
\bar{m}=\frac{\left(K_{m}\left(V_{r e f}-V_{s}\right)-m\right)}{T_{m}}
$$

Burada, $m$ modülasyon genliği, $\mathrm{K}_{\mathrm{m}}$ modülasyon katsayısı, $\mathrm{V}_{\text {ref }}$ referans gerilim, $\mathrm{V}_{\mathrm{s}}$ ölçülen şebeke gerilimi, $\mathrm{T}_{\mathrm{m}}$ modülasyon zaman sabitidir. Genlik kontrolü bir sinırlandırıcı tarafindan denetlenmektedir. Yakıt hücresinin DC gücü şebekeye aktif ve reaktif güç olarak ilave edilmektedir. Güç sistemine ilave edilen aktif ve reaktif güç eşitlikleri denklem (21) ve denklem (22)'de gösterilmiştir.

$$
\begin{gathered}
P_{s}=\frac{V_{t} V_{s}}{X_{t}} \sin \left(\theta_{t}-\theta_{s}\right) \\
Q_{s}=\frac{V_{t} V_{s}}{X_{t}} \cos \left(\theta_{t}-\theta_{s}\right)
\end{gathered}
$$

Burada, $V_{t}$ yakıt hücresinin terminal gerilimini, $X_{t}$ transformatör reaktansını, $\theta_{t}$ yakıt hücresinin terminal gerilim açısını ve $\theta_{\mathrm{s}}$ kaynak geriliminin açısını ifade eder. Kaynak gerilim açısının ifadesi ise denklem (23)'te gösterilmiştir.

$\theta_{t}=\theta_{s}+a \sin \left(\frac{X_{t} I_{k}}{K_{m} V_{s}}\right)$

Denklem (22)'de yer alan terminal gerilim açı ifadesi ile denklem (23)'teki reaktif güç eşitliği birleştirildiğinde denklem (24) elde edilir.

$Q_{s}=\frac{V_{s}^{2}}{X_{t}}+\frac{V_{s} V_{t}}{X_{t}} \sqrt{1-\left(\frac{X_{t} I_{k}}{K_{m} V_{s}}\right)^{2}}$

Evirici genliğinin ve referans gerilim değerinin güç akışı çözümlemesinde kullanılan ifadeleri denklem (25) ve denklem (26)'da verilmiştir.

$$
\begin{aligned}
& e_{g 0}=-\frac{X_{t}}{V_{s}\left(V_{t} / K_{m}\right)} \sqrt{P_{g}^{2}+\left(Q_{q}+\frac{V_{g}^{2}}{X_{t}}\right)^{2}} \\
& V_{r e f}=V_{g}+\left(\frac{e_{g}}{K_{m}}\right)
\end{aligned}
$$

Burada, e evirici genliğini, e $e_{g}$ başlangıç evirici genliğini, $V_{g}$ bağlı olduğu bara gerilimini, $P_{g}$ bağlı olduğu bara aktif gücünü, $Q_{g}$ ise bağlı olduğu bara reaktif gücünü ifade etmektedir.

\section{GERILIM KARARLILIĞI}

Gerilim kararlılığı temel olarak tüm baraların geriliminin kabul edilebilir limitlerde sabit tutulması olarak ifade edilmektedir. Sistemin kararlı olması için, arıza sonrasında ve normal çalışma koşulları altında güç sisteminin tüm baralarında gerilimin kabul edilebilir limitlerde olması gerekmektedir. Aksi halde sistem kararsızdır. Ayrıca, sisteme reaktif güç verilerek ya da sistemden reaktif güç çekilerek de gerilim kararlılığı kontrol edilebilmektedir. Güç sisteminde reaktif güç verme veya çekme 
durumlarında sistemin kararlı olarak adlandırmak için tüm sistemdeki bara gerilimlerinin çalışma sınırları içerisinde bulunması gerekmektedir. Gerilim kararlılığı durumunun incelenmesi için çatallanma analizinden faydalanılmaktadır. Çatallanma analizinin temel açıklaması, dinamik bir sistemde, sistem parametreleri değiştiğinde fazların yapısının da değişmesidir. Yerel çatallanma analizinin incelenmesi için çatallanma noktasına yakın olan vektör diferansiyel denklemler ile analiz edilir. $\mathrm{Bu}$ analiz yapılırken güç sistemindeki yük değişiklikleri anlamına gelen bir yükleme parametresi belirtilmektedir. Bir güç sisteminde, yüklenme parametresi sistemdeki yük değişiklikleri anlamına gelir ve buna bağlı olarak aktif güç ile reaktif güç değerleri de değişmiş olur. Çatallanma analiz yaklaşımı Şekil 5'te gösterilmiştir.

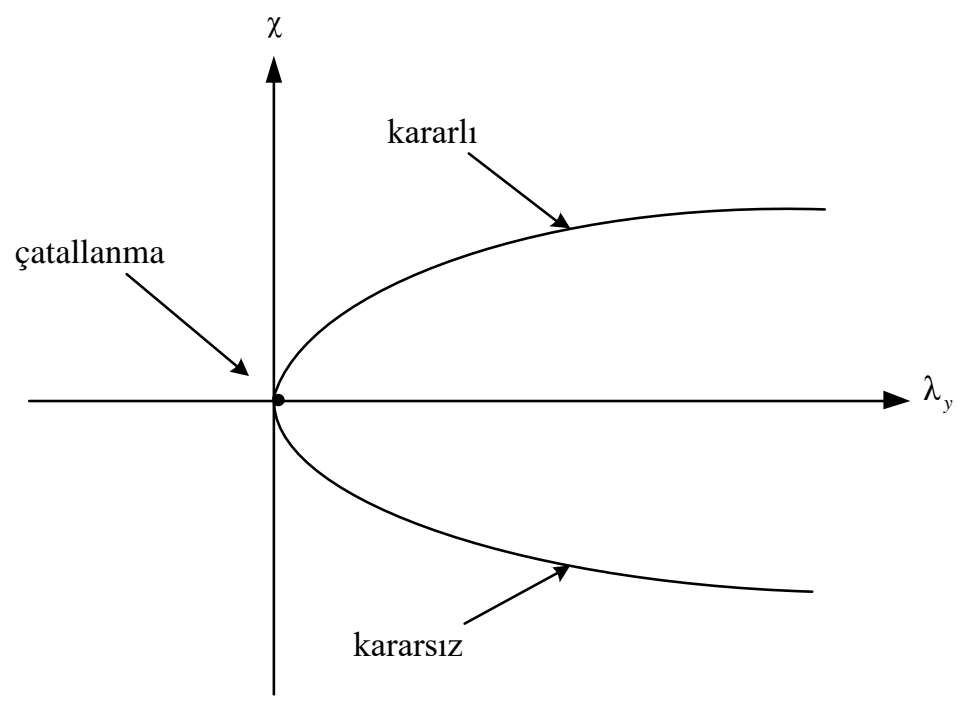

Şekil 5.Çatallanma analizi

Çatallanma analizi yapılırken çatallanma denkleminden yararlanılmaktadır. Çatallanma analizi için kullanılacak olan ifade denklem (27)'de gösterilmiştir.

$\dot{x}=\lambda-x^{2}=f(x, \lambda)$

$\mathrm{Bu}$ eşitlikte, $\mathrm{x}$ durum değişkenidir. $\mathrm{f}(\mathrm{x}, \lambda)$ fonksiyonu değiştiğinde sistemin kararlı ve kararsız olduğu bölgelerin tanımlaması yapılabilir. Eğer $\lambda<0$ olduğu durumda ise sistemin denge durumunda olmadığ görülür. Eğer $\lambda>0$ olduğu durumda ise iki tane denge durumu karşımıza çıkmaktadır. Bunlardan bir tanesi denge noktası diğeri ise denge noktası değildir. Bu durumların haricinde $\lambda=0$ olduğu durumda denge durumu oluşur ve sistem değişiminin kararlı olduğu elde edilir [17].

\section{BENZETİM CALISMMASI}

Benzetim çalışması Uluslararası Elektrik Elektronik Mühendisliği (IEEE) 14 baralı güç sistemi üzerinde test edilmiştir. Benzetim çalışmasında Güç Sistemleri Analizi Programı (PSAT) kullanılmıştır [18].IEEE 14 baralı güç sistemi devre modeli Şekil 6' da gösterilmiştir. 


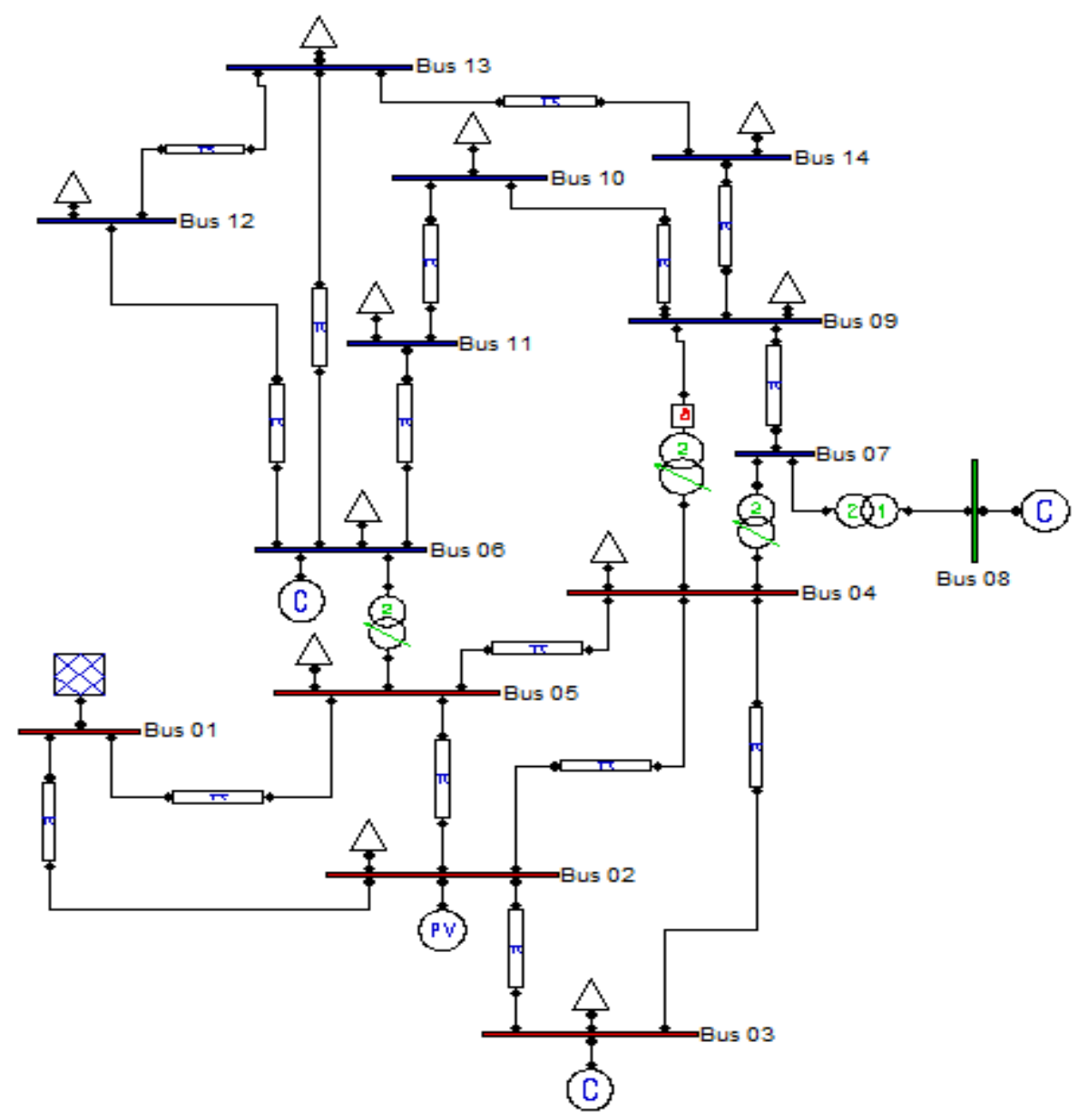

Şekil 6.14 baralı güç sistemi devre modeli

IEEE 14 baralı güç sisteminde 1 adet salınım barası, 4 adet generatörbarası ve 9 adet yük barası bulunmaktadır. IEEE 14 baralı sistemin $5-6,4-8$ ve 4-9 iletim hatlarında gerilimi düşüren transformatörler kullanılmıştır. 5-6 ve 4-9 numaralı iletim hatları arasındaki transformatörlerde kademe değiştirme ve faz kaydırma işlemleri yapılmaktadır. Yapılan benzetim çalışması 6 senaryodan oluşmaktadır. İlk senaryoda sürekli durum çalışmadaki gerilim kararlılı̆̆ analiz, ikinci senaryoda 9 ile 14 numaralı baralar arasına bağlanan UPFC ile sürekli durum çalıșmadaki analiz, üçüncü senaryoda 9 ile 14 numaralı baralar arasına bağlanan UPFC ile 14 numaralı baraya bağlanan yakıt hücresinin beraber kullanıldığındaki sürekli durum çalışmadaki analiz, dördüncü senaryoda geçici durumda çalışmadaki analiz, beşinci senaryoda 9 ile 14 numaralı baralar arasına bağlanan UPFC ile geçici durumda çalışmadaki analiz, altıncı senaryoda 9 ile 14 numaralı baralar arasına bağlanan UPFC ile 14 numaralı baraya bağlanan yakıt hücresinin beraber kullanıldığındaki geçici durum çalışmadaki analiz incelenmiştir. Enerji depolama elemanlarından yakıt hücresinin gücü \% 10 artış olarak gösterilmiştir.

\section{BENZETIM CALISMASI SONUCLARI}

IEEE 14 baralı güç 6 senaryo için sürekli yük akışı analiz gerçekleştirilmiştir. Sürekli yük akış1 esnasında bara gerilimi en düşük olan baralar 4, 5, 9 ve 14 numaralı baralardır. Sürekli yük akış1 sonucunda 6 senaryo sonucunda yük baralarının gerilim-maksimum yüklenme parametre değerleri sirasiyla 2.8286 p.u., 2.9638 p.u., 3.0257 p.u., 1.5846 p.u., 1.6351 p.u., ve 1.6407 p.u. olarak bulunmuştur. 6 senaryoya göre elde edilen gerilim-maksimum yüklenme parametre değerleri Şekil 7'de gösterilirken, bara gerilim profilleri Şekil 8' de gösterilmiştir. 


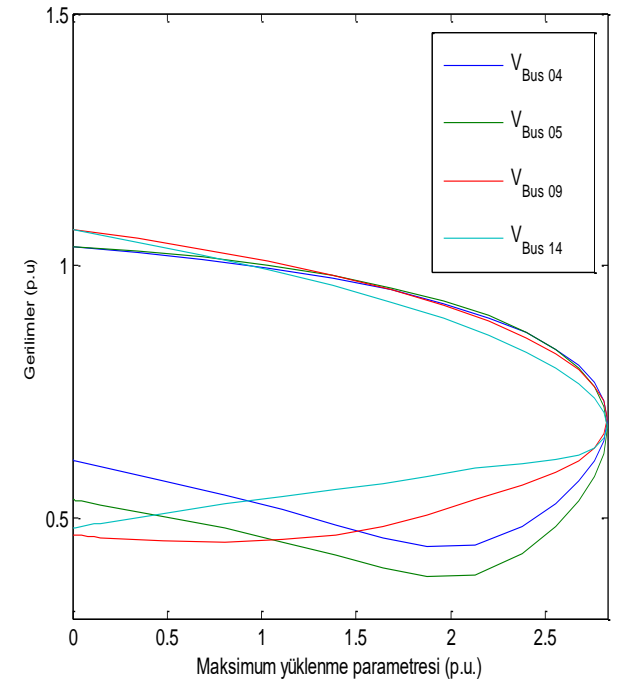

(a)

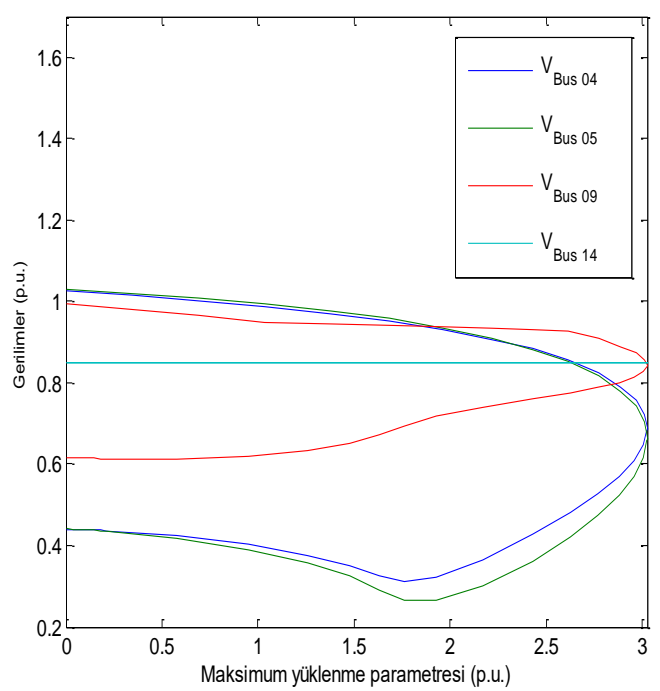

(c)

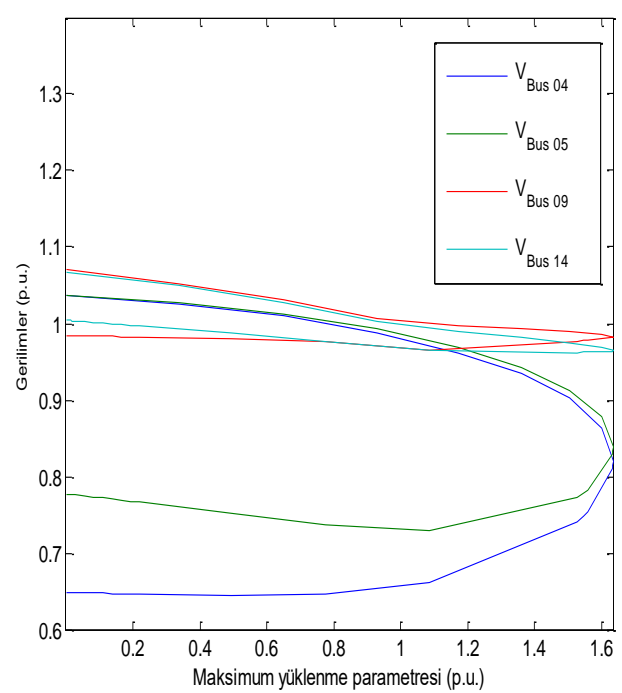

(e)

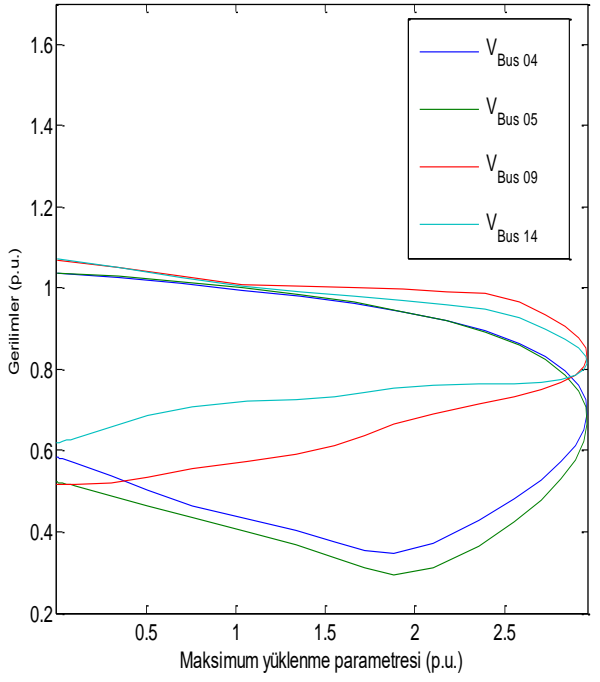

(b)

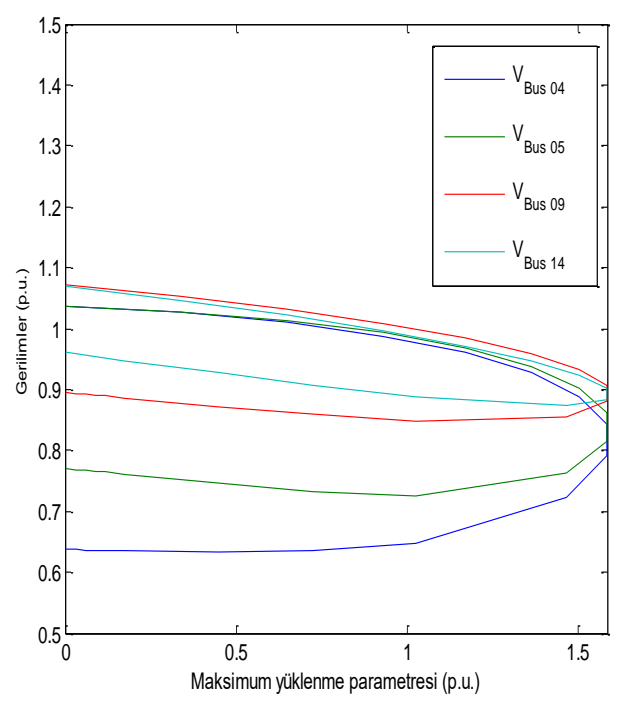

(d)

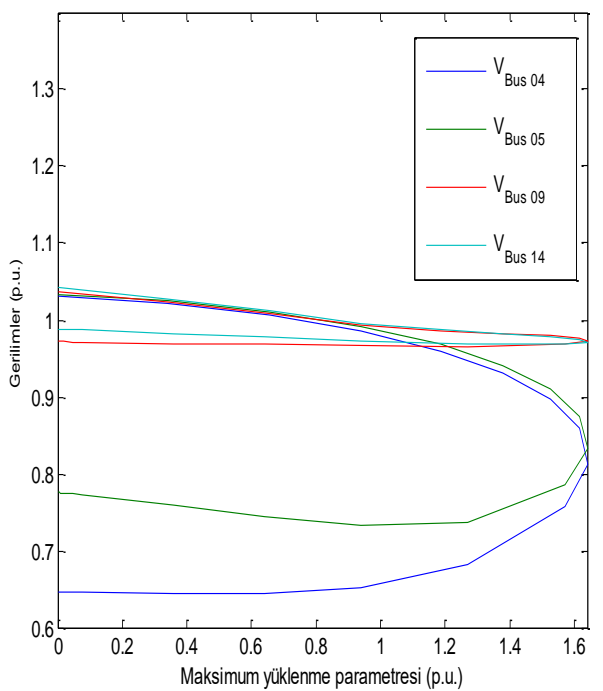

(f)

Şekil 7. Farklı senaryolara göre elde edilen gerilim-maksimum yüklenme parametre değerleri 

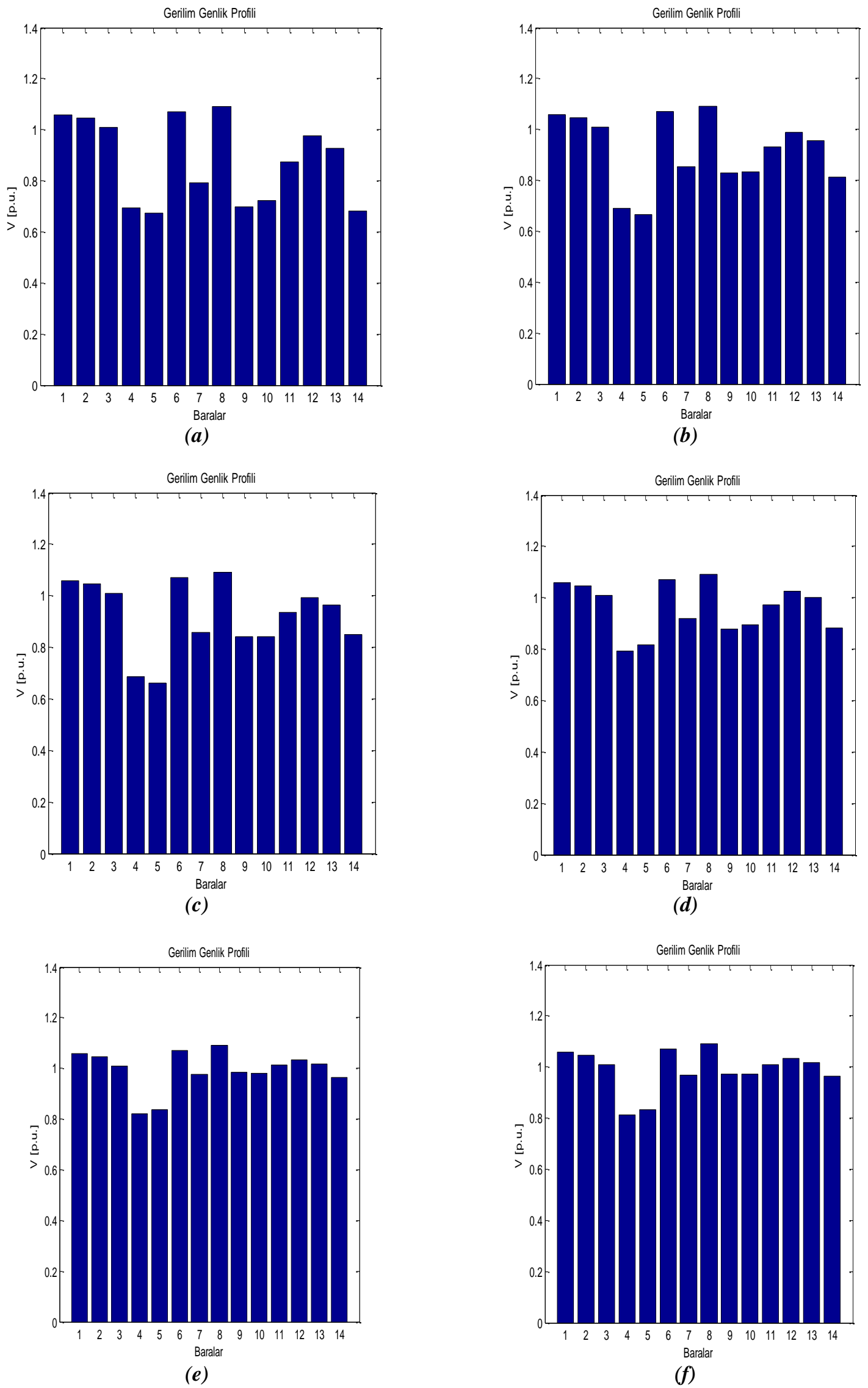

Şekil 8. Farkl senaryolara göre elde edilen bara genlik profilleri 
İlk senaryoda sürekli durum çalışmadaki gerilim kararlılığı analizinde bara gerilimlerinin durumları, ikinci senaryoda ve üçüncü senaryolar ile karşılaştırılmıştır. UPFC'nin bağlanması ile 9 ile 14 numaralı baraların gerilimleri sürekli yük akışı sonucunda artmıştır. Dahası 14 numaralı baraya bağlanan yakıt hücresi sayesinde 14 numaralı baranın daha da yükseldiği görülmüştür. Geçici durum çalışmada sürekli durum çalışmaya göre bara gerilim profillerinde ciddi bir azalma olmuştur. Geçici durum çalışmada 9 ile 14 numaralı baralar arasına bağlanan UPFC ile bara gerilim profillerinin arttığı görülmüştür. Son senaryoda ise yakıt hücresinin bağlanması ile 14 numaralı baranın gerilimin genlik değeri artmaya devam etmiştir. Yakıt hücresinin diğer yüzdelik artması ile elde edilen maksimum yüklenme parametre değerleri Tablo 1 ve Tablo 2'de gösterilmiştir.

Tablo1.9-14 numaralı hatlarda bulunan UPFC'nin farklı güçlerdeki yakıt hücresi ile kullanımındaki maksimum yüklenme parametre değerleri

\begin{tabular}{cc}
\hline $\begin{array}{c}\text { Yakıt hücresinin güç } \\
\text { sistemine vermiş olduğu } \\
\text { yüzdelik güç değeri } \\
(\%)\end{array}$ & $\begin{array}{c}\text { Maksimum yüklenme } \\
\text { parametre değeri }\end{array}$ \\
\hline 20 & 3.0795 \\
\hline 30 & 3.1366 \\
\hline 40 & 3.1857 \\
\hline 50 & 3.2420 \\
\hline 60 & 3.2907 \\
\hline 70 & 3.3411 \\
\hline 80 & 3.3917 \\
\hline 90 & 3.4440 \\
\hline 100 & 3.4964 \\
\hline
\end{tabular}

Tablo2. Geçici durum esnasinda 9-14 numaralı hatlarda bulunan UPFC'nin farkll güçlerdeki yaktt hücresi ile kullanımindaki maksimum yüklenme parametre değerleri

\begin{tabular}{cc}
\hline $\begin{array}{c}\text { Yakıt hücresinin güç } \\
\text { sistemine vermiş olduğu } \\
\text { yüzdelik güç değeri } \\
(\%)\end{array}$ & $\begin{array}{c}\text { Maksimum yüklenme } \\
\text { parametre değeri }\end{array}$ \\
\hline 20 & 1.6526 \\
\hline 30 & 1.6645 \\
\hline 40 & 1.6777 \\
\hline 50 & 1.6886 \\
\hline 60 & 1.6999 \\
\hline 70 & 1.7133 \\
\hline 80 & 1.7245 \\
\hline 90 & 1.7389 \\
\hline 100 & 1.7492 \\
\hline
\end{tabular}

Tablo 1 ve Tablo 2'de elde edilen sonuçlar neticesinde belli oranlarda yakıt hücresinin güç sistemine vermiş olduğu yüzdelik güçlerde sistemin maksimum yüklenme parametre değerlerinin arttı̆̆ görülmüştür.

\section{SONUCLAR}

Bu çalışmada, güç sistemlerinin çalışma koşullarının iyileştirilmesi ve dinamik durumlarda hızlı cevap verebilme yeteneğine sahip olan UPFC'nin statik ve dinamik davranışları incelenmiştir. Genel olarak sistemde aktif-reaktif güç, gerilim, açı, akım ve empedans kontrolünü sağlamada UPFC'nin 
avantajlarından yararlanarak bu çalışmada sürekli ve geçici durum analizleri incelenmiş olup, dahası günümüzde yaygın olarak kullanılan EDS elemanlarından yakıt hücresinin gerilim kararlılı̆̆ı üzerinde ne gibi etkiler oluşturabileceği konusunda UPFC ile birlikte kullanılması amaçlanmıştır. Sürekli ve geçici durum çalışmalarda UPFC ve yakıt hücresi ile birlikte 14 baralı güç sisteminin güvenirlik ve bara çalışma koşullarının iyileştirmesi açısından etkili sonuçlar verdiği görülmüştür. Çok makinalı güç sisteminde gerilim-maksimum yüklenme parametresinde artış olurken, bağlı oldukları baraların gerilim genlik profilleri iyileşmiştir. Bu çalışma ile yakıt hücresinin diğer FACTS cihazları ile kullanımı söz konusu olurken, farklı güç sistem analizleri için diğer çalışmalarda kolaylık sağlamıştır.

\section{KAYNAKLAR}

[1] D. B. Valle ve P. B. Araujo, "The influence of GUPFC FACTS device on small signal stability of the electrical power systems," International Journal of Electrical Power \& Energy Systems, c. 65, ss. 299-306, 2015.

[2] R. K. Pandey ve N. K. Singh, "UPFC control parameter identification for effective power oscillation damping," International Journal of Electrical Power \& Energy Systems, c. 31, s. 6, ss. 269276, 2009.

[3] Z. H. U. Xinyao, J. I. N. Meng, K. O. N. G. Xiangping, Z. H. A. O. Jingbo, L. I. U. Jiankun ve Z. H. O. U. Qian, "Subsynchronous resonance and its mitigation for power system with unified power flow controller," Journal of Modern Power Systems and Clean Energy, c. 6, s. 1, ss. 181-189, 2018.

[4] J. Ling, H. Ji, C. Yu, S. Wang, D. Yu ve S. Jiang, "Design of UPFC sub-synchronous oscillation damping controller based on modal control," In 2018 China International Conference on Electricity Distribution (CICED), Tianjin, China, 2018, ss. 1439-1443.

[5] D. K. Raju, B. S. Umre, A. S. Junghare, ve B. C. Babu, "Mitigation of subsynchronous resonance with fractional-order PI based UPFC controller," Mechanical Systems and Signal Processing, c. 85, ss. 698-715, 2017.

[6] M. R. Qader, "Design and simulation of a different innovation controller-based UPFC (unified power flow controller) for the enhancement of power quality," Energy, c. 89, ss. 576-592, 2015.

[7] Y. U. A. N. Yubo, L. I. Peng, K. O. N. G. Xiangping, L. I. U. Jiankun, L. I. Qun ve W. A. N. G. Ye, "Harmonic influence analysis of unified power flow controller based on modular multilevel converter," Journal of Modern Power Systems and Clean Energy, c.4, s. 1, ss. 10-18, 2016.

[8] L. Jiankun, Z. Ningyu, Z. Xinyao, X. Ke ve C. Zhe, "Method of calculating the maximum transmission capability with unified power flow controller," The Journal of Engineering, c. 2017, s. 13, ss. 1963-1968, 2017.

[9] B. Xu ve A. Abur, "State estimation of systems with UPFCs using the interior point method," IEEE Transactions on Power Systems, c. 19, s. 3, ss. 1635-1641, 2004.

[10] C. V. Suresh ve S. S. Raju, "Mathematical modeling and analysis of a generalized unified power flow controller with device rating methodology," International Journal on Electrical Engineering and Informatics, c. 7, s. 1, ss. 59-78, 2015.

[11] M. M. Hosseini-Biyouki, S. Jashfar, B. Vahidi ve H. Askarian-Abyaneh, "Impact of optimal unified power flow controller in electrical transmission systems in reducing transmission cost," Electric Power Components and Systems, c. 45, s. 16, ss. 1762-1772, 2017. 
[12] M. A. Kamarposhti ve H. Lesani, "Effects of STATCOM, TCSC, SSSC and UPFC on static voltage stability," Electrical Engineering, c. 93, s. 1, ss. 33-42, 2011.

[13] M. A. Kamarposhti, M. Alinezhad, H. Lesani ve N. Talebi, "Comparison of SVC, STATCOM, TCSC, and UPFC controllers for static voltage stability evaluated by continuation power flow method," In 2008 IEEE Canada Electric Power Conference, Vancouver, Canada, 2008, ss. 1-8.

[14] R. Natesan ve G. Radman, "Effects of STATCOM, SSSC and UPFC on voltage stability," in Proc. Thirty-Sixth Southeastern Symposium on System Theory, Atlanta, USA, 2004, ss. 546-550.

[15] C. A. Canizares, F. L. Alvarado, C. L. DeMarco, I. Dobson ve W. F. Long, "Voltage collapse and transient energy function analyses of AC/DC systems," Ph.D. dissertation, Wisconsin Univ, Madison, USA, 1991.

[16] B. Yildirim ve M. T. Gencoglu, "Oscillatory stability and eigen value analysis of power system with microgrid,” Electrical Engineering, c. 100, s. 4, ss. 2351-2360, 2018.

[17] H. D. Chiang, A. J. Flueck, K. S. Shah ve N. Balu, "CPFLOW: A practical tool for tracing power system steady-state stationary behavior due to load and generation variations," IEEE Transactions on Power Systems, c. 10, s.2, ss. 623-634, 1995.

[18] F. Milano, "An open source power system analysis toolbox," IEEE Transactions on Power Systems, c. 20, s. 3, ss. 1199-1206, 2005. 